\title{
Impact of a web-based review quiz on the learning outcomes of dental hygiene students in Japan
}

\author{
Hugo Maruyama $^{1 *}$, Shikiko Tsukamoto ${ }^{2}$, Hiromi Toujo ${ }^{2}$, Takayuki Nambu ${ }^{1}$, Chiho \\ Mashimo $^{1}$, Toshinori Okinaga ${ }^{1}$ \\ ${ }^{1}$ Department of Bacteriology, Osaka Dental University, Hirakata, Japan \\ ${ }^{2}$ Osaka Dental Hygienist College, Osaka, Japan \\ * Correspondence:
}

Hugo Maruyama

maruyama@cc.osaka-dent.ac.jp

ORCID: 0000-0002-2190-7109

\begin{abstract}
Active participation of students is paramount not only for their learning experiences but also for their academic performance. Therefore, various methods have been developed and proven to help students achieve active learning. However, several shortcomings in these methods have been indicated as increasing students' sense of burden and discomfort, eventually preventing them from benefiting sufficiently. This study aimed to determine the efficiency of a low-load web-based review quiz built by the researchers on Google Forms to enhance students' reviewing habits and active class participation. Participants in this study were 53 first-year dental hygiene students in a 10-class microbiology course. After each class, all students were given the web-based quiz to prepare for a paper-based review test, which assessed the learning of the content covered in the previous classes. We analyzed the correlations between frequency of participation in the web-based quiz and the average scores of the weekly review tests or the final examination scores. Consequently, voluntary participation in the web-based quiz positively correlated with both short-term and long-term students' learning outcomes. Through this web-based quiz during the first year of the dental hygiene program, students can develop the "self-learning attitude" needed to pass the national examination.
\end{abstract}

Keywords: active learning, web-based quiz, Google Forms, reviewing habits, smartphone

Running Title: Web-based review quiz 


\section{Introduction}

Students in dental hygiene programs in Japan usually learn basic microbiology and immunology in the first year. In some dental hygiene schools, classes are taught by faculty members from dental universities, such as the authors of this paper. A common feature of these programs is that students rarely review the content learned in the classroom, which leads to them failing their final examinations. As performance in the first year can influence the learning attitude in subsequent years of college life, it is necessary to provide measures that enable students to learn actively (Narita, 2018).

Active learning has been applied in Japanese universities for students of various academic years (Yamaji and Kawagoe, 2012), given its importance in learning and performance. Various methods have been developed and used to facilitate active learning. For example, pre-tests used to prepare students for what they will learn in schools for training nurses have been shown to have a positive effect on learning (Yamauchi, 2019). Further, gamebased methods have proven effective in student learning (Farrell et al., 2011; Felszeghy et al., 2019). Moreover, online learning has been shown as being particularly useful for learning microbiology (Johnson, 2008). All these methods help students prepare for and actively participate in classes.

Despite their advantages, active learning strategies have several shortcomings. For example, active learning-type classes give students a sense of burden and discomfort, which eventually prevents them from benefiting sufficiently (Chikada and Sugino, 2015; Matsubara, 2019).

We hypothesized that providing a low-load method to review classroom learnings would enhance their learning ability. Web-based quiz has been used to assist students' learning (Amran et al., 2016; Sivakumar, 2019). This study aimed to develop and evaluate the efficiency of a web-based quiz on the learning outcomes of dental hygiene students. To this end, we evaluated whether taking this web-based quiz has a positive effect on students' learning outcomes by comparing frequency of participation in the web-based quiz with the average scores of weekly review tests or the final examination scores. The questionnaire comprised a web-based review quiz aimed to enable students to review the content learned in class. 


\section{Materials and Methods}

Participants in this study were 53 first-year students at Osaka Dental Hygienist College. This study was conducted in 2018 on the required microbiology and immunology course. In nine of the ten weekly classes of the course, all students took a paper-based review test during the class period, which aimed to assess the learning of the content covered in the previous class. Students were told that the average score of the review tests will be included in the final grading as much as $10 \%$. All students attended a final exam after taking all the classes. The score of the final exam comprised $90 \%$ of the student's final grade (Figure 1).

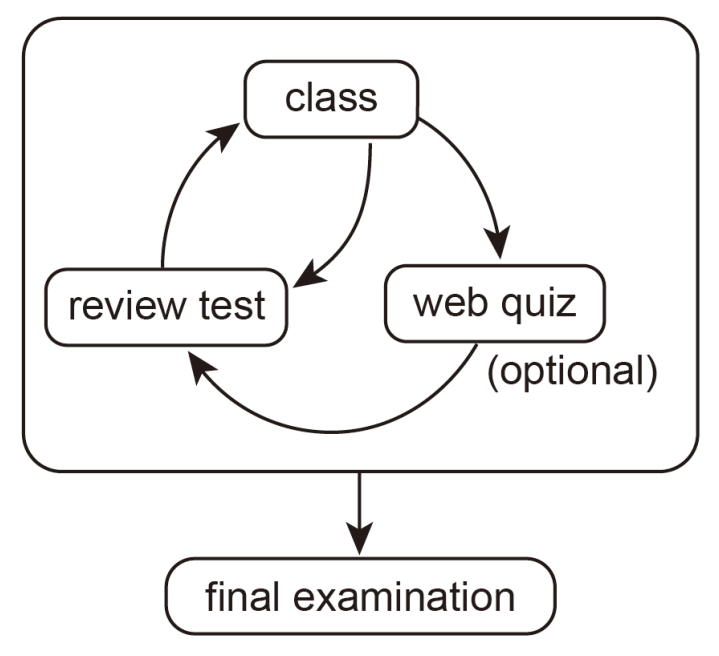

Figure 1. Illustration of the learning cycle. After a microbiology class, all students take a paper-based review test on the class the following week. Before the test, students could take a web-based quiz on related topics. Both the review test and the web-based quiz are multiple-choice questions.

Prior to taking the paper-based review test, students had the opportunity to participate in a web-based quiz (Figure 1) designed to help them prepare for the paper-based review test. As for its structure, the quiz comprised multiple-choice questions that addressed the same content as the following review test. The quiz was developed using the "make this a quiz" functionality of Google Forms. In addition to being a free and easy-to-use questionnaire creation platform (Sivakumar, 2019), Google Forms allows students to view their scores and the correct answers immediately after taking the quiz (Figure 2). Further, the tool allows the teacher to view the details of all students' scores exported in real time to a spreadsheet (Google Sheet) (Figure 2).

Each web-based quiz was made available on the Internet for students a few days before they had to take the corresponding paper-based review test and web-based quizzes were provided seven times during the course. Students could take the web-based review quiz anywhere using their personal devices connected to the Internet. Participation in the quiz was not mandatory, and students were informed that the quiz scores would not be included in their final grading. After the course, the correlations between participation in the web-based quiz, the average score on the paper-based review test, and the score on the final examination were analyzed. 
students

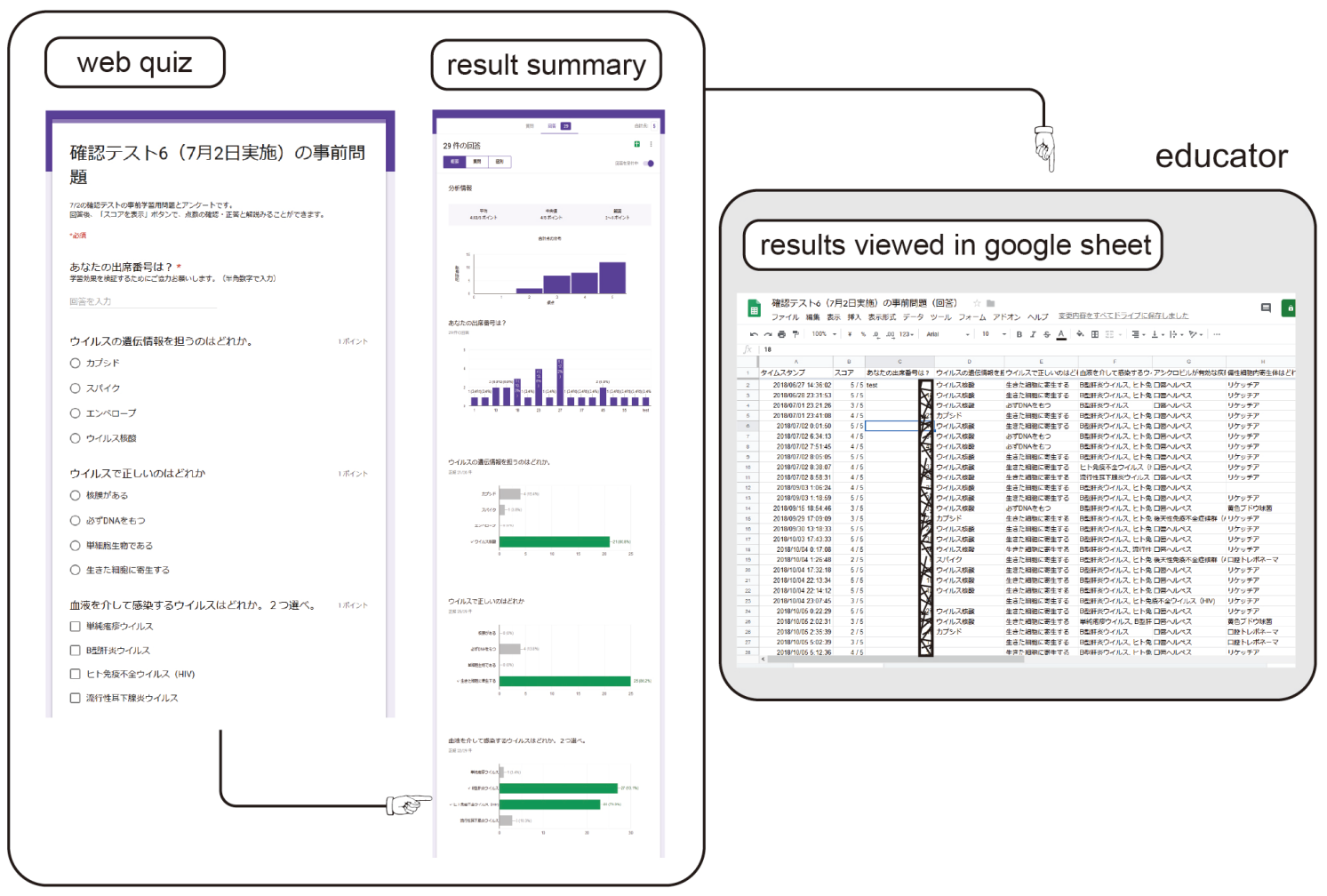

Figure 2. How the web-based quiz works for the students and the educator. Students can immediately see their score and the correct answer for each question, as well as the summary of other students' answers. The educator can see the detailed result for each student immediately on a Google sheet. 


\section{Results}

The examination scores of students who participated in the non-mandatory web-based quiz were compared with those of students who did not participate in order to evaluate the correlation between voluntary participation in the web-based quiz and learning outcomes. To this end, it was clarified that the participation or score in the web-based quiz would not be included in the student's grade.

Regarding participation in the web-based quiz, 25 of the 53 students participated at least once. The average participation was 2.2 times among all students and 4.8 times among students who participated at least once (Figure 3A). With regard to the scores in the paper-based review tests, the average score for all students was $6.0 \pm 0.9$ (mean $\pm \mathrm{SD}$ ) of the total score of 10 (Figure 3B). All students took the final examination after finishing all course classes. The average score on the final examination was $75.1 \pm 14.8$ (Figure 3C).

(A)

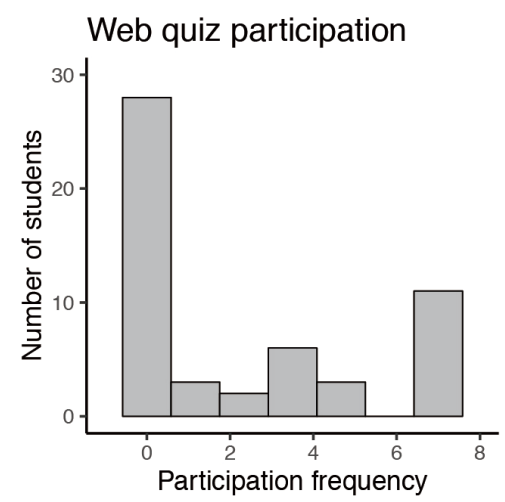

(B)

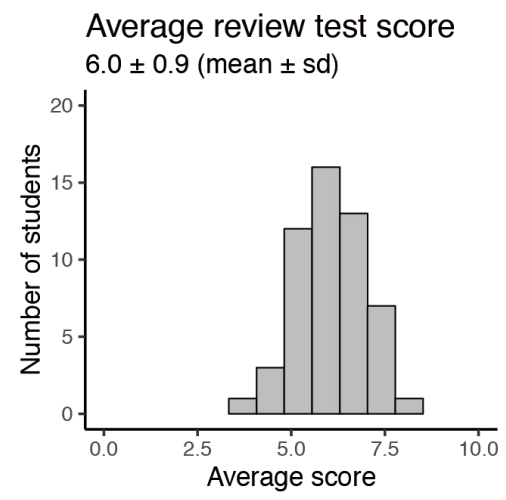

(C)

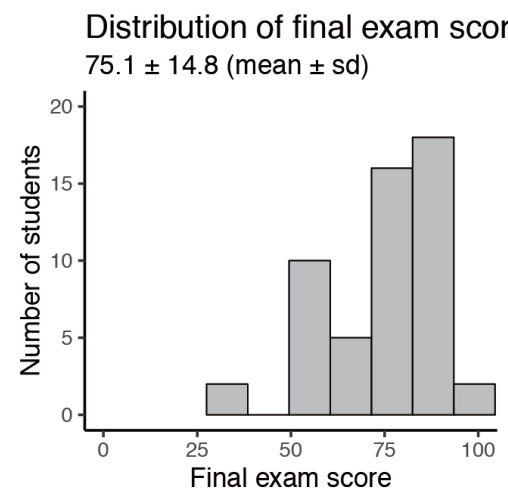

Figure 3. Summary of participation to the web-based test, average score of the review test, and distribution of the final exam score. (a) Histogram showing frequency of student participation in the web-based quiz. (b) Histogram showing each student' s average score in the review test. (c) Histogram showing each student' s score in the final examination.

Next, the correlation between test scores and frequency of participation in the webbased quiz was analyzed. The scores on the review test (average) and the final examination had a positive correlation (Kendall's $\tau=0.39, p=0.00006$ ) (Figure 4A). This is reasonable, considering that questions in the final examination were partly adopted from the review tests, which students had already taken once.

Finally, we investigated whether participation in the web-based quiz influences shortand long-term learning outcomes. The correlations between frequency of participation in the web-based quiz and examination scores were analyzed. Participation in the web-based quiz positively correlated with both the average review test score (Kendall's $\tau=0.24, p=0.03$ ) (Figure 4B) and the final examination score (Kendall's $\tau=0.27, \mathrm{p}=0.013$ ) (Figure 4C). In addition, approximately half of the students who did not participate in any web-based quiz performed poorly on the final examination (Figure 4C). Overall, these results indicate that voluntary participation in the web-based quiz correlates with outcomes of both short-term 
(review test) and long-term (final examination) learning.

(A)

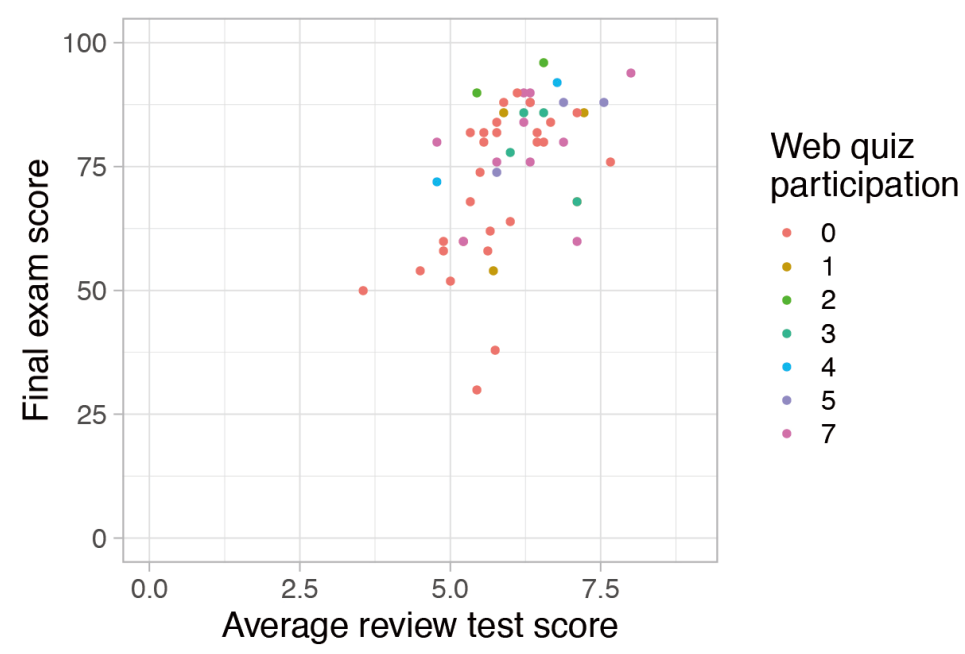

(B)

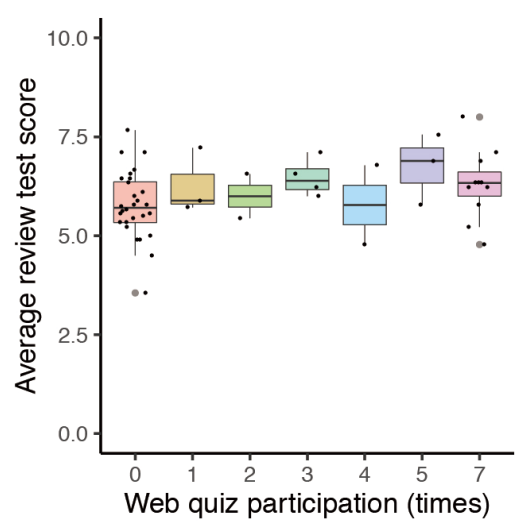

(C)

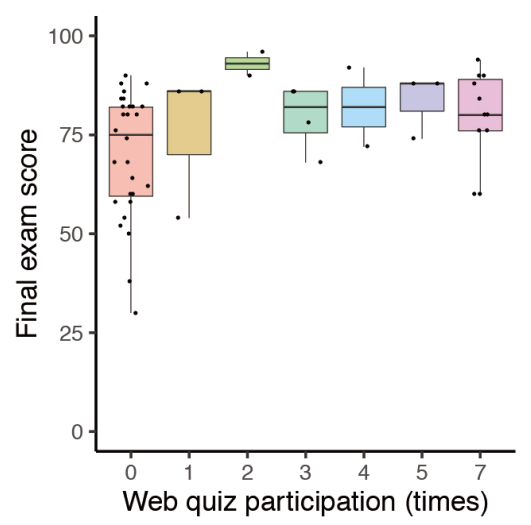

Figure 4. Correlations between test scores and web-test participation. (a) Scatter plot showing the correlation between the average review test score and the final examination score (Kendall' s $\mathrm{T}=0.39, \mathrm{p}=0.00006$ ). The color of the dots indicates frequency of student participation in the web-based quiz. (b) Correlation between the average review test score and times participated in the web-based quiz (Kendall' $s \mathrm{~T}=0.24, p=0.03$ ). Each dot indicates one student. Boxplots summarize students' scores classified by times those students participated in the quiz. (c) Correlation between final exam score and frequency of participation in the web quiz (Kendall' $s \mathrm{~T}=0.27, p=0.013$ ). 


\section{Discussion}

This study developed and assessed the efficiency of a web-based review quiz on the learning outcomes of dental hygiene students. Consequently, voluntary participation in the nonmandatory web-based quiz correlated with both short- (review test) and long-term (final examination) learning outcomes. Approximately half of the students who did not participate in any web-based quiz performed poorly in the final examination (Figure 4C). This probably reflects the lack of regular reviewing habits among these students. Thus, it would be effective to make this web-based quiz mandatory to encourage students to practice reviewing the content given in class regularly. Accordingly, a voluntary learning task has been shown to enhance students' learning motivation (Sakai et al., 2017).

Through this web-based quiz during the first year of the dental hygiene program students can develop the "self-learning attitude" that is necessary to pass the national examination. This type of low-load quiz may also be useful in education for dental students, since these students face the same problem of lack of active participation and reviewing habits. In addition, quizzes using Google Forms may be useful for repeated education of healthcare professionals in the practice of infection control, which has been challenged by declining awareness over time (Gamoh et al., 2018).

It was assumed that most students participated in the web-based quiz using their smartphones, considering the widespread use of these devices among youngsters worldwide, including college and university students (Chen et al., 2017). The increase in the number of smartphone users is followed by criticisms about the various downsides in the use of smart devices, including Internet or smartphone addiction (Tateno et al., 2019a; Tateno et al., 2019b; Martínez-Sánchez et al., 2020). However, several studies suggest that the use of such technologies has a positive effect on academic performance (Ma et al., 2018; Han and Yi, 2019). Moreover, the importance of gaining Information and Communication Technology (ICT) literacy has been widely recognized worldwide (Fukumoto, 2017). Thus, we believe that the use of these devices in a positive way should be promoted by carefully avoiding their shortcomings.

In conclusion, it was verified that participation in the web-based review quiz introduced in a microbiology course as a part of dental hygiene training has a positive correlation with academic performance. Through this web-based quiz during the first year of the program, dental hygiene students can develop the "self-learning attitude" necessary to pass the national examination. Given that today's youngsters are comfortable using smartphones, the use of these devices has the effect of encouraging learning without burdening students. In this study, only a few students participated in the web-based quiz, probably knowing that it would not be included in their final grade. Thus, devising a method to increase student participation in such a quiz would encourage students to develop reviewing habits.

\section{Acknowledgements}

We would like to thank Editage (www.editage.com) for English language editing. 


\section{References}

Amran, R., Yokoyama, F., and Nishino, K. (2016). Development of Active Learning Methods of English in Japanese High Schools to Support Student Activities in Group Discussions. Procedia Computer Science 96, 1471-1478. doi: 10.1016/j.procs.2016.08.193.

Chen, N., Yamashita, Y., and Kubota, Y. (2017). The Possibility for the Use of Smart Devices in the University Education: Based on the Results of the Comparative Survey between the Foreign and Japanese Students. Kansai Kokusai Daigaku Kenkyu Kiyou 18, 37-45. http://id.nii.ac.jp/1084/00000481/.

Chikada, M., and Sugino, T. (2015). Students' Perceptions of Active Learning in Undergraduate Education. Daigaku Kyouiku Kenkyu (23), 1-17. https://ci.nii.ac.jp/naid/40020455363/.

Farrell, D., Kostkova, P., Lazareck, L., Weerasinghe, D., Weinberg, J., Lecky, D.M., et al. (2011). Developing e-Bug web games to teach microbiology. J Antimicrob Chemother 66 Suppl 5(SUPPL. 5), v33-38. doi: 10.1093/jac/dkr121.

Felszeghy, S., Pasonen-Seppanen, S., Koskela, A., Nieminen, P., Harkonen, K., Paldanius, K.M.A., et al. (2019). Using online game-based platforms to improve student performance and engagement in histology teaching (? Use of gamification in a histology course: An innovative strategy). BMC Medical Education 19(273), 1-11. doi: 10.1186/s12909-019-1701-0.

Fukumoto, T. (2017). ICT literacy and competencies for the 21st century and national curriculum. Kokuritsu Kyouiku Seisaku Kenkyusho Kiyou 146, 79-93.

http://ci.nii.ac.jp/naid/120006424354/.

Gamoh, S., Akiyama, H., Maruyama, H., Ohshita, N., Nakayama, M., Matsumoto, K., et al. (2018). Compliance with infection control practices when taking dental $\mathrm{x}$-rays: Survey of a Japanese dental school. Clin Exp Dent Res 4(5), 158-166. doi: 10.1002/cre2.124.

Han, S., and Yi, Y.J. (2019). How does the smartphone usage of college students affect academic performance? Journal of Computer Assisted Learning 35(1), 13-22. doi: 10.1111/jcal.12306.

Johnson, M.T. (2008). Impact of Online Learning Modules on Medical Student Microbiology Examination Scores. Journal of Microbiology \& Biology Education 9(1), 25-29. doi: 10.1128/jmbe.v9.91.

Ma, S., Steger, D.G., Doolittle, P.E., and Stewart, A.C. (2018). Improved Academic Performance and Student Perceptions of Learning Through Use of a Cell Phone-Based Personal Response System. Journal of Food Science Education 17(1), 27-32. doi: 10.1111/1541-4329.12131.

Martínez-Sánchez, I., Goig-Martínez, R.M., Álvarez-Rodríguez, J., and Fernández-Cruz, M. (2020). Factors Contributing to Mobile Phone Dependence Amongst Young People-Educational Implications. Sustainability 12(6), 2554-2554. doi: 10.3390/su12062554.

Matsubara, E. (2019). Active learning of the physics of radiology in a seminar for third - year students. Journal of Osaka Dental University 53(2), 127-132. doi: 10.18905/jodu.53.2_127.

Narita, A. (2018). Identification and Management of Students with Poor Academic Achievements in Higher Education Institutions. Rigakuryoho Kagaku 33(1), 33-37. doi: 10.1589/rika.33.33.

Sakai, K., Abe, I., Fujita, D., and Naka, K. (2017). Raising Student Efforts through Voluntary Learning Tasks in Information Literacy Classes as Outcome of Deploying Learning Advisors. Journal of Psychology Research 7(5). doi: 10.17265/2159-5542/2017.05.001.

Sivakumar, R. (2019). Google forms in education. Journal of Contemporary Educational Research and Innovations 9(1), 33-39.

Tateno, M., Kim, D.-J., Teo, A.R., Skokauskas, N., Guerrero, A.P.S., and Kato, T.A. (2019a). Smartphone Addiction in Japanese College Students: Usefulness of the Japanese Version of the Smartphone Addiction Scale as a Screening Tool for a New Form of Internet Addiction. Psychiatry Investigation 16(2), 115-120. doi: 10.30773/pi.2018.12.25.2.

Tateno, M., Teo, A.R., Ukai, W., Kanazawa, J., Katsuki, R., Kubo, H., et al. (2019b). Internet Addiction, Smartphone Addiction, and Hikikomori Trait in Japanese Young Adult: Social Isolation and Social Network. Front Psychiatry 10, 455. doi: 10.3389/fpsyt.2019.00455. 
Yamaji, H., and Kawagoe, A. (2012). Case Reports of Systematic Implementation of Active Learning in Japanese Universities. Nagasaki Univeristy Daigaku Kyouiku Kinou Kaihatsu Center Bulletin 3, 67-85. http://hdl.handle.net/10069/28476.

Yamauchi, A. (2019). Benefits and problems of courses for independent learning of nursing techniques-With an introduction of both the pre-test and technology assessment sheet. The bulletin of Ryotokuji University 13, 111-123. doi: 10.18933/00000356. 


\section{Figure legends}

Figure 1. Illustration of the learning cycle. After a microbiology class, all students take a paperbased review test on the class the following week. Before the test, students could take a webbased quiz on related topics. Both the review test and the web-based quiz are multiple-choice questions.

Figure 2. How the web-based quiz works for the students and the educator. Students can immediately see their score and the correct answer for each question, as well as the summary of other students' answers. The educator can see the detailed result for each student immediately on a Google sheet.

Figure 3. Summary of participation to the web-based test, average score of the review test, and distribution of the final exam score. (a) Histogram showing frequency of student participation in the web-based quiz. (b) Histogram showing each student's average score in the review test. (c) Histogram showing each student's score in the final examination.

Figure 4. Correlations between test scores and web-test participation. (a) Scatter plot showing the correlation between the average review test score and the final examination score (Kendall's $\tau=0.39, p=0.00006$ ). The color of the dots indicates frequency of student participation in the web-based quiz. (b) Correlation between the average review test score and times participated in the web-based quiz (Kendall's $\tau=0.24, p=0.03$ ). Each dot indicates one student. Boxplots summarize students' scores classified by times those students participated in the quiz. (c) Correlation between final exam score and frequency of participation in the web quiz (Kendall's $\tau=0.27, \mathrm{p}=0.013$ ). 